Review

\title{
Non-Centrifugal Sugar (NCS) and Health: A Review on Functional Components and Health Benefits
}

\author{
Dina Zidan (D) and Azrina Azlan*(D) \\ Department of Nutrition, Faculty of Medicine and Health Science, Universiti Putra Malaysia, \\ Serdang 43400, Selangor, Malaysia; gs62061@student.upm.edu.my \\ * Correspondence: azrinaaz@upm.edu.my
}

Citation: Zidan, D.; Azlan, A. Non-Centrifugal Sugar (NCS) and Health: A Review on Functional Components and Health Benefits. Appl. Sci. 2022, 12, 460. https:// doi.org/10.3390/app12010460

Academic Editor: Philip Prinz

Received: 10 October 2021

Accepted: 28 December 2021

Published: 4 January 2022

Publisher's Note: MDPI stays neutral with regard to jurisdictional claims in published maps and institutional affiliations.

Copyright: (C) 2022 by the authors. Licensee MDPI, Basel, Switzerland. This article is an open access article distributed under the terms and conditions of the Creative Commons Attribution (CC BY) license (https:// creativecommons.org/licenses/by/ $4.0 /)$.

\begin{abstract}
Non-centrifugal sugar (NCS) is the scientific term the Food and Agriculture Organization (FAO) uses to define a solid product, produced by sugarcane juice evaporation, which is unrefined or minimally refined. NCS is referred to in various names globally, the most significant ones are whole cane sugar, panela (Latin America), jaggery (India) and kokuto (Japan). NCS contains minerals, bioactive compounds, flavonoids and phenolic acids, which have therapeutic potentials from time immemorial. Even though the bioactive property is dependent on the composition, which relies mainly on the agronomic conditions and production process, NCS possesses antioxidant and antiinflammatory properties. Hence, substituting the consumption of refined sugar with NCS might be helpful in the control of chronic diseases generally connected to oxidative stress and inflammation. Experimental facts from in vitro and in vivo models have proven that NCS plays an essential role in weight management, maintaining insulin sensitivity and preventing neurodegenerative diseases. NCS has also shown hypoglycemic and hypolipidemic effects. This review aims to synopsize the recent literature pertaining to the benefits of NCS in human health. The NCS can be considered a nutraceutical and functional food. However, detailed and regulated studies are important to enhance the beneficial effects in human and animal interventions.
\end{abstract}

Keywords: non-centrifugal sugar; brown sugar; polyphenol; antioxidant; diabetes; obesity

\section{Introduction}

Unrefined sugar is generally obtained from sugarcane (Saccharum officinarum), palm (Borassus flabellifer) and coconut (Cocos nucifera plant.). The most common raw material used for unrefined sugar production is extracted juice from sugarcane stalks [1]. Non-centrifugal sugar (NCS) is the technical term used by the Food and Agriculture Organization of the United Nations (FAO) [2] for a traditional minimally processed sweetener from sugar cane (Saccharum officinarum L.). The World Customs Organization (WCO) [3] defines it as follows: "The product contains only natural anhedral microcrystals, of irregular shape, not visible to the naked eye, which are surrounded by residues of molasses and other constituents of sugar cane". Six steps are involved in manufacturing traditional NCS: (1) cutting sugarcane; (2) pressing the sugar cane stalk and obtaining the juice; (3) clarifying the juice; (4) heating the sugar cane juice to evaporate the water (more than $130{ }^{\circ} \mathrm{C}$ ) and obtaining the sugar syrup; (5) further heating and concentrating the sugar syrup at $140{ }^{\circ} \mathrm{C}$ and obtaining the semi-solid product; (6) pouring the semi-solid product, that contains a little water, into molds to enable cooling and natural formation [4]. The manufacturing process is either presented in solid form (blocks or bricks) or granulated form. NCS is available in many countries under different local names, including panela (Latin America), jaggery (India), Kokuto (Japan) and Gula Melaka (Malaysia) [5,6]. India remains the top producer of NCS, followed by Colombia [7]. Sucrose is the essential component in NCS, followed by reducing sugar, water, and insoluble matter, such as fat, proteins, and minerals [6].

Since NCS product does not require an intense refining process, NCS is full of vitamins and bioactive compounds found naturally in sugarcane, such as phenolic acids (caffeic, 
chlorogenic and coumaric acids), flavonoids (naringenin, tricin, apigenin and luteolin derivative) and long-chain alcohols known as policosanols (PCs). NCS products contain 20 essential amino acids and have a unique taste and aroma [5,8-13]. In addition, Citrulline and $\gamma$-aminobutyric acid (GABA) are also found in NCS products [8]. NCS is known as 'medicinal sugar', which is used for pharmaceutical formulations due to its richness in nutraceutical and functional compounds [14]. Many health-promoting properties of NCS have been reported, including immuno-protective effects, anti-toxicity, anti-anaemia effect, antioxidant properties, cytoprotective effects, antiatherosclerotic function and anticarcinogenic effects as well as protective effects against diabetes, inflammation, obesity, dyslipidemia, and neurodegeneration disease [13-18]. Nutritional components, bioactive and the sensory profile of NCS largely depends on the agronomic factors (genotypes of cane, soil types, fertilization, and harvest) and industrial processing conditions. Hence, the NCS quality depends on the traditional systems of harvest, transformation and final product in each producing area and nation [19]. The present review summarizes in vitro and in vivo studies on the benefits and efficacy of NCS.

\section{Physical Properties}

Various types of unrefined sugar products have a lower $\mathrm{pH}$ value ( $\mathrm{pH} 4.55-6.3$ ) compared to refined sugars $[17,20]$. Carbonation, i.e., the addition of limewater to remove impurities present in sugarcane juice, is responsible for the high $\mathrm{pH}$ of refined sugar. In contrast, the presence of different phenolic compounds, flavonoids, and natural preservatives, such as citric acid, in unrefined sugars can reduce $\mathrm{pH}$ values $[17,20]$. The total soluble solids (TSS) value indicates the sweetness of unrefined sugar ranging from $9.60-25^{\circ}$ Brix $[1,20]$. The sweetness of NCS is not sharp as with pure sucrose, glucose, fructose, and artificial sweeteners due to the presence of other chemical components in the NCS, such as fat, protein, minerals and phytocompounds $[1,20]$. Solubilities of NCS products were reported in the range (32.65-34.18\%) [21]. NCS made from sugarcane have a color value ranging from 2641.7 to 32,600 IU $[1,17,20,21]$. The color value of NCS from sugarcane was reported to be higher than unrefined sugar from palm and coconut [1]. The brown color in unrefined sugar is mainly because of the presence of molasses, amino acid and phytocompound pigments. In addition, the excessive utilization of lime in the purification process, destruction of sucrose, oxidation, and reduction of phytocompounds, and high temperature during the heating process could result in the browning of unrefined sugars [20]. Moisture content and water activity are two main properties of food products, indicating their shelf-life stability. Moisture content and water activity of NCS products ranged from $1.5-25.9 \%$ and 0.42 to 0.56 , respectively $[17,20,21]$. The variation in moisture among unrefined sugar products is due to the differences in their processing conditions [19]. Unrefined cane sugar produced by an industrial method was recorded to have lower moisture content $(2.08-3.96 \%)$ compared with cane sugar produced by traditional methods [1]. Besides, the moisture content was reported to be higher in NCS bricks (6.5\%) compared to the granulated NCS (2.74 \%) [22]. A high moisture content enhances the dissolution of crystals, cobblestone synthesis, microbial deterioration, and biochemical break-down reactions, all of which lessen the shelf life of sugars [20]. Unrefined sugar had high acidity of $0.55 \%$ [21]. In other work, the acidity value of unrefined sugar was higher than that of refined sugar, indicating fewer processing and refining steps of the unrefined product [23]. Moreover, the high acidity of unrefined sugar makes it useful as a natural sweetener, whereby it helps control the acidity of a beverage added with unrefined sugar [23]. Generally, the physical properties of unrefined sugar are affected by several factors, including cane varieties, manufacturing process conditions such as open system (traditional method) and closed system (industrial method), time and temperature [1,20]. Different methods of removal of impurities to purify raw juice also influence the characteristics of the unrefined sugar products where chemicals, such as calcium oxide, calcium hydroxide and polymers, are used in industrial production, while rough filtration is used in traditional production methods [1]. 


\section{Chemical Composition}

NCS is a natural sweetener composed of sugar, water, and other substances, such as amino acids, minerals, vitamins, polyphenolic compounds, volatile compounds, and other trace substances. As such, it is rich in macro- and micronutrients. The mean chemical composition of various forms of NCS is shown in Table 1. Sucrose is an essential component, in the range of 76.55 and $89.48 \%$, followed by monosaccharides, glucose and fructose and water $(1.5-15.8 \%)[8,19]$. Discrepancies in the processing conditions cause a comparatively broad range of moisture, protein, and fat content below $2 \%$ [19]. NCS is composed of an abundance of both primary and trace minerals in the range of 1648.11-2971.90 mg/100 g [8]. Calcium, magnesium, phosphorus, chloride, and potassium are the most presented minerals in NCS products, as shown in Table 2 [20]. NCS is a formidable source of iron and contains more iron and copper content than refined sugar [14]. Iron is the component responsible for the anti-anaemia effect of NCS. The cause-and-effect relationship between iron consumption and haemoglobin and red blood cells increase is welcomed by the European Food Safety Agency. As such, Europe permits such claims [24]. Selenium has also been detected in minimally refined brown sugar (MRBS) [23]. Since selenium is an insulin mimic [25], NCS might be a recommended option for patients with diabetes. NCS contains up to 21 amino acids, where the predominant components are asparagine, aspartic acid, phenylalanine, and alanine [8]. Additionally, NCS also contains health-beneficial $\gamma$-aminobutyric acid, known as GABA, at levels of 2.32-7.54 mg/100 g [8]. GABA amino acids are involved in the regulation of synaptic transmission, promoting neuronal development and relaxation, and preventing sleeplessness and depression [26]. NCS contains a trace amount of $B$ vitamins such as thiamine (B1), riboflavin (B2), niacin (B3), pantothenic (B5), Pyridoxine (B6), folic acid (B9) and vitamin C, E and A, as shown in Table 3 [19]. No less than two rare sugars with functional capacity have been determined in NCS: D-Psicose and cyclodextrans or Cycloisomaltooligosaccharides [27,28]. Policosanols (PCs) were also found in NCS products [15]. PCs are a mixture of primary long-chain alcohols, which possess cholesterol and lipid-reducing properties [21,29].

Table 1. General Chemical Composition of NCS [8,19].

\begin{tabular}{ccc}
\hline Nutrients & Unit & Quantity \\
\hline Moisture & $\mathrm{g}$ & $1.5-15.8$ \\
Carbohydrate & $\mathrm{g}$ & $83.90-97.2$ \\
Total sugar & $\mathrm{g}$ & $87.5-95.4$ \\
Sucrose & $\mathrm{g}$ & $76.55-89.48$ \\
Reducing sugar & $\mathrm{g}$ & $3.69-10.5$ \\
Fiber & $\mathrm{g}$ & 0.00 \\
Protein & $\mathrm{g}$ & $0.37-1.7$ \\
Fat & $\mathrm{g}$ & $0 . .00-0.10$ \\
Ash & $\mathrm{g}$ & $0.3-3.6$ \\
Amino Acids & $\mathrm{mg}$ & $205.22-805.28$ \\
Total Minerals & $\mathrm{mg}$ & $1648.11-2971.90$ \\
\hline
\end{tabular}


Table 2. Minerals in NCS $[19,23]$.

\begin{tabular}{ccc}
\hline Minerals & Unit & Quantity \\
\hline Calcium & $\mathrm{mg}$ & $13.70-240.00$ \\
Chloride & $\mathrm{mg}$ & $5.30-250.00$ \\
Cobalt & $\mu \mathrm{g}$ & 9.90 \\
Copper & $\mathrm{mg}$ & $0.17-8.50$ \\
Chromium & $\mu \mathrm{g}$ & $11.90-16.00$ \\
Iodine & $\mu \mathrm{g}$ & 0.01 \\
Iron & $\mathrm{mg}$ & $1.60-12.50$ \\
Magnesium & $\mathrm{mg}$ & $31.00-120.00$ \\
Manganese & $\mathrm{mg}$ & $0.35-1.66$ \\
Phosphorus & $\mathrm{mg}$ & $2.00-125.00$ \\
Potassium & $\mathrm{mg}$ & $14.05-1100.00$ \\
Selenium & $\mu \mathrm{mg}$ & 0.02 \\
Sodium & $\mathrm{mg}$ & $15.50-79.00$ \\
Zinc & $\mathrm{mg}$ & $0.10-1.76$ \\
\hline
\end{tabular}

Table 3. Vitamins in NCS [19].

\begin{tabular}{ccc}
\hline Vitamins & Unit & Quantity \\
\hline Vitamin A & $\mathrm{mg}$ & 1.90 \\
B1 (Thiamin) & $\mathrm{mg}$ & 0.03 \\
B2 (Riboflavin) & $\mathrm{mg}$ & 0.07 \\
B3 (Niacin) & $\mathrm{mg}$ & 2.14 \\
B5 (Pantothenic acid) & $\mathrm{mg}$ & 0.70 \\
B6 (Pyridoxine) & $\mathrm{mg}$ & 0.21 \\
B9 (Folic acid) & $\mu \mathrm{g}$ & 3.33 \\
Vitamin C & $\mathrm{mg}$ & 4.23 \\
Vitamin E & $\mathrm{mg}$ & 55.0 \\
\hline
\end{tabular}

\section{Phytochemicals Compounds}

The lack of molasses removal during brown sugar production causes the end products to contain various bioactive compounds that possess biological functions [8]. Polyphenols represent the major bioactive molecules present in NCS. Polyphenolic compounds can be categorized into flavonoids (flavones, flavanols, flavanones, anthocyanin, chalcones and isoflavones) and non-flavonoids (phenolic acids) [30]. The profile of polyphenols in NCS has been largely investigated. Some phenolic acids found in NCS include $p$-hydroxybenzoic acid, vanillic acid, $p$-coumaric acid, ferulic acid and rosmarinic acid. Flavonoids are mainly luteolin, kaempferol, naringenin, apigenin and anthocyanins (3-rutinoside cyanidin, cyanidin and pelargonidin), as shown in Table 4 [18,23,31]. Heatinduced phenolics were also reported in sugarcane products. Heat-induced phenolics can be generated by splitting high molecular weight into smaller molecular weight monomeric phenols [32]. Asikin et al. [8] reported total phenolic content (TPC) in the range of 176.97-294.40 mg GAE/100 g between different eight brown sugar samples. The amount and type of the polyphenols are influenced mainly by the agronomic factors (genotypes of cane, soil types, fertilization and harvest, among others), parameters of NCS production (thermal treatments) and production process (industrial process or traditional process by the farmer) [21,33]. Azlan et al. [23] reported a higher content of TPC in minimally refined brown sugar (MRBS) (2.67 mg GAE/100 g sample) compared to brown sugar (BS) (1.73 mg GAE/100 g sample) as MRBS undergoes fewer refining processes than brown sugar. Additionally, industrial cane sugar from Japan showed significantly higher TPC (1745.6-1911.4 GAE/100 g) than cane sugar from Thailand (1108.5-1550.5 mg GAE/100 g). Industrial brown sugar from Thailand is manufactured by a partial centrifugal technique involving partial molasses removal, while Japanese brown sugar is processed without molasses removal [1]. Light, dark and raw BS contains a TPC of 0.004, 0.38, 0.42, and 
$0.58 \mathrm{mg} \mathrm{GAE} / \mathrm{g}$, respectively [17]. Weerawatanakorn et al. [1] reported moderate correlations between TPC and total flavonoid content (TFC) levels with the International Commission for Uniform Methods of Sugar Analysis (ICUMSA) color value of the unrefined sugar $(\mathrm{R} 2=0.6504$ and 0.7797 , respectively). The data suggests that a darker coloration could be a potential and straightforward indicator in obtaining BS with superior bioactive compounds. Cane sugar showed superior TPC, TFC and antioxidant activities compared to unrefined sugar from palm and coconut, particularly in Thai and Japanese products [1].

Table 4. Detected phenolic acids in NCS.

\begin{tabular}{ccc}
\hline Phytochemical Molecules & Quantity $\mathbf{( m g} / \mathbf{1 0 0} \mathbf{g})$ & References \\
\hline -hydroxybenzoic acid & Phenolic Acids & \\
Benzoic acid & $0.022-0.44$ & {$[18,34]$} \\
Caffeic acid & $0.47-0.84$ & {$[23]$} \\
Vanillic acid & $0.065-7.6$ & {$[23,31,34]$} \\
$p$-coumaric acid & $0.36-1.86$ & {$[18,22,23,34]$} \\
Gallic acids & $0.080-1.98$ & {$[22,23,31,34,35]$} \\
Ferulic acid & $0.15-1.43$ & {$[34]$} \\
Rosmarinic acid & $0.0035-5.6$ & {$[18,22,23,31,34]$} \\
Syringic acid & $<0.01$ & {$[18]$} \\
Chlorogenic acid & $0.076-0.547$ & {$[22,23,34]$} \\
Protocatechuic acid & $0.089-28$ & {$[34,36,37]$} \\
Cinnamic acids & $0.012-0.089$ & {$[22,34]$} \\
& $0.49-38$ & {$[31]$} \\
Luteolin & Flavonoids & {$[18,31]$} \\
Kaempferol & $0.48-2.5$ & {$[18]$} \\
Naringenin & 0.081 & {$[18]$} \\
Apigenin & 0.006 & {$[18,31]$} \\
Tricin & $0.008-19$ & {$[23,31]$} \\
Flavones & $0.71-13.0$ & {$[31]$} \\
& $2.4-33$ & {$[18]$} \\
3-rutinoside cyanidin & Anthocyanins & {$[18]$} \\
Cyanidin & 0.13 & {$[18]$} \\
Pelargonidin & 0.22 &
\end{tabular}

\section{Type of Brown Sugar}

A wide variety of non-refined brown sugar (BS) from sugarcane attracts food and beverage formulators and consumers to make their choice. They constitute a complete spectrum of colors and textures between off-white to dark brown sugar [36]. Brown sugar manufactured from sugarcane can be split into two major categories: (1) centrifuged brown cane sugar and (2) non-centrifuged brown cane sugar [36], Figure 1. Centrifuged brown cane sugars are now mainly produced in many industrial countries by two primary methods. First, coating refined white sugar with several quantities of cane molasses is the most used method. The quantity of molasses put determines the intensity of brown color, with colors ranging from light to dark brown [36]. Secondly, a more traditional but uncommon technique to make centrifuged brown sugar is manufacturing them in the refinery from a low-purity liquor [37]. Such products include Turbinado sugar (equally called Demerara) and Muscovado sugar (alternatively called Barbados) [36]. Turbinado sugar is a golden raw sugar that has been centrifuged to get rid of some molasses covering the surface of the crystal. Turbinado sugar is also marketed as "raw cane sugar" in the United States [36]. Compared to Turbinado sugar, Muscovado sugar is very dark brown and has a strong molasses flavor [37]. 


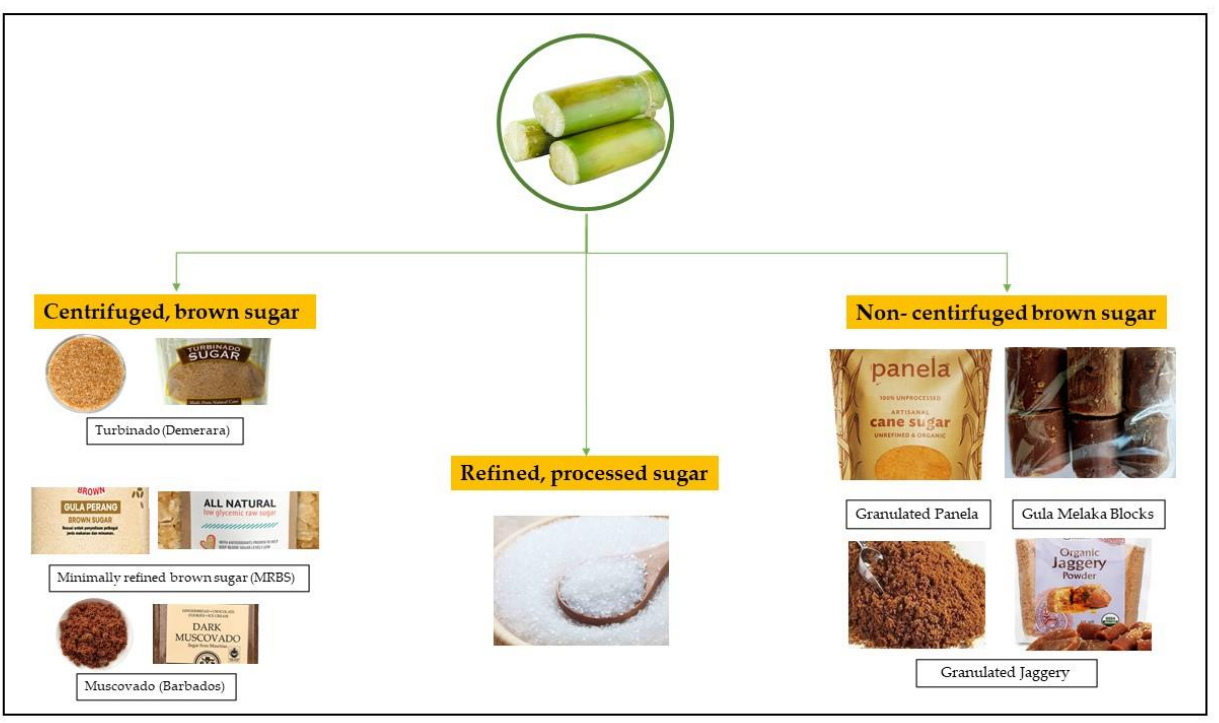

Figure 1. Various types of sugar processed from sugarcane.

On the other hand, non-centrifugal sugar (NCS) is a whole cane sugar that is not centrifuged, and the molasses is not separated from the crystal, as can be seen in Figure 2. Depending on the country of origin, whole cane sugar goes by many different names, including panela in Latin America, jaggery in India and kokuto in Japan (Table 5) [19]. Generally, centrifugal, and non-centrifugal brown cane sugar show a superior nutritional value and bioactive molecule content compared to refined white cane sugar due to the molasses content and the process requiring less refining on different products. Therefore, when considering the health value, unrefined sugarcane sweeteners are the main sweeteners to opt for, even in the level of other unrefined natural sweeteners obtained from coconut, palm, or date [1,37]. This is due to the fact that sugarcane juice has a complex combination of polyphenols and minerals, which most of them retain during the production of brown sugar [32]. Even though phenolic compounds concentrate across sugarcane-products production, they are got rid of, in refined white cane sugar and concentrated in the byproduct blackstrap molasses [38]. Eggleston [37] reported that molasses contains about $3000 \mathrm{mg} / \mathrm{L}$ total phenol content, equivalent to pomegranate juice $(\sim 2850 \mathrm{mg} / \mathrm{L})$. According to Eggleston and Aita [32], cane sweeteners (centrifuged and non-centrifuged) contain large amounts of antioxidants. Therefore, cane sweeteners are the most attractive healthy sweeteners to consumers due to their crystalline shape compared to natural sugar from honey, date, and maple. Indeed, most "natural" sweeteners contain antioxidants and are being marketed as "antioxidant-rich". Certain artificial sweeteners and other competitive sweeteners are being enriched with antioxidants as they are void of such nutrients. Yet the sugar industry is not marketing natural brown sugar as rich in natural antioxidants [32]. Indeed, the major concern and setback in the brown sugar industry is the significant variation in its functional and nutritional components within the same product in one country or region and between differently named products of different countries [19]. This variation can be attributed mainly to the differences in the manufacturing processes, seasonal and geographical differences in the sugar cane crop. The characteristics of crystalline sugar that can be affected by variability include ICUMSA, moisture, reducing sugars, ash, micronutrients. In this context, with increasing awareness among consumers of the potential health benefits of unrefined brown sugar, there is also recent industrial efforts in increasing specifically the standardization and optimization of bioactive compounds in the brown sugar products. For example, there has been recent interest in brown sugar products known as minimally refined brown sugar (MRBS) [23,39], which are manufactured in a mill and/or refinery using higher volume industrial centrifuge. The benefit of modern high-volume equipment is that near infrared-analyzing equipment is installed, which improves the consistent specification of final brown sugar products by $60 \%$ [40-43]. In particular, total 
polyphenols can be detected and retained, and also reducing sugar (fructose and glucose) can be detected and monitored through this manufacturing process [43]. In the most recent study, MRBS was reported to have a lower GI (54), improved satiety, glycemic profiles, and plasma total antioxidant capacity (TAC) compared to refined sugar in healthy subjects [39].

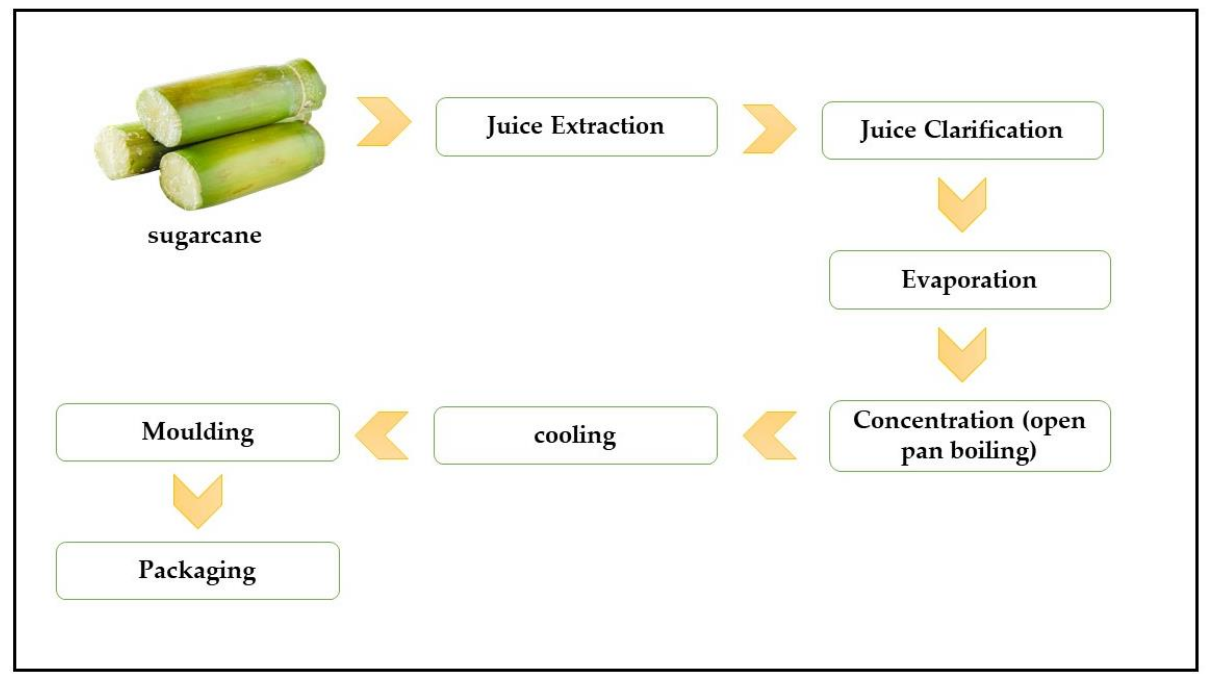

Figure 2. Production diagram of NCS.

Table 5. Different NCS names in different countries [19].

\begin{tabular}{cc}
\hline Name & Country \\
\hline Vollrohrzucker & Germany \\
Black sugar (Kurosato), and Kokuto & Japan \\
Evaporated cane juice and raw sugar & Europe, North America and USA \\
Chancaca & Peru and Bolivia \\
Azúcar Integral and Azúcar Panela & Latin America, Argentina \\
Gula Java and Gula Merah & Indonesia \\
Gula Melaka & Malaysia \\
Dulce and Tapa Dulce & Costa Rica and Nicaragua \\
Panocha and Panutsa & Philippines \\
Gur & India and Pakistan \\
Hakuru and Vellam & Sri Lanka \\
Rapadura & Brazil and Guatemala \\
Jaggery & India, Nigeria, Kenya and South Africa \\
Moscovado & Philippines \\
Panela & Ecuador, Guatemala, Panama and Venezuela \\
Papelón & Venezuela \\
Piloncillo & Mexico \\
Namtan Tanode & Thailand \\
Unrefined Muscovado & UK \\
Sukari Njumru & Colombia, Ecuang \\
Raspadura & Panama \\
\hline
\end{tabular}

\section{Biological Properties of NCS}

\subsection{Antioxidant Properties}

Reactive oxygen species (ROS) production can cause protein carboxylation, DNA damage and lipid peroxidation, resulting in several human diseases, such as atherosclerosis, diabetes, hypertension, ageing, Alzheimer's disease, kidney disease, and cancer [44]. The use of dietary antioxidants is known to be an essential strategy for inactivating ROS. Antioxidants are molecules that can give an electron to free radicals. As such, they neutralize, reduce, or remove the free radical effectiveness to damage cells and biomolecules, such as nucleic acids, proteins, and lipids [44]. 
NCS exhibits intense antioxidant activity. The NCS antioxidant property is mainly due to the presence of polyphenols. The NCS major constituents that cause the antioxidant abilities are phenolic acids and flavonoids $[18,23]$. The phenolic acids in NCS that possess antioxidative ability are caffeic acid, $p$-coumaric acid, ferulic acid, syringic acid, vanillic acid and chlorogenic acid [23]. Therefore, NCS, given alone or together with conventional therapy, could manage chronic diseases linked to oxidative stress.

Various investigations showed that NCS could avert pathological conditions caused by oxidative stress. In vitro studies revealed that NCS could remove free radicals (peroxyl radicals and nitric oxide) and reduce ferric cations, chelate metal ions, inhibit lipid peroxidation and $\beta$-carotene bleaching [16-18,20,21,23,31,33,34,45,46]. Suk Lee et al. [20] reported the potency of the NCS samples on the inactivation of cellular ROS induced by superoxide anions and hydrogen peroxide. Jaggery and BS showed cytoprotective capacities against tert-butyl hydroperoxide, hydrogen peroxide-induced oxidative damage of NIH 3T3 fibroblasts and human erythrocytes [16]. Additionally, animal studies have revealed that jaggary could enhance the antioxidant defence system in rodents by stimulating the functions of antioxidant enzymes including superoxide dismutase, catalase, glutathione peroxidase and glutathione S-transferase, and increase the amounts of reduced glutathione [35,47]. Kinjo et al. [35] investigated the effect of the NCS fraction of kokuto on stressed mice during the treatment period of 7 days. Since stress leads to a surge in ROS, the efficacy of NCS in improving the antioxidant system was assessed through the measurement of radical scavenging activity and SOD activity in serum and liver. SOD activity and the antioxidant effect in serum and liver were significantly increased with all tested concentrations of NCS (25\%, 50\%, 75\% and 100\%). Grabek-Lejko and Tomczyk-Ulanowska, [48] reported that replacing refined white sugar with unrefined sugarcane sweeteners increases the daily intake of antioxidants to 28.68 mmoles of FRAP equivalent, which is equivalent to the consumption of $1 \mathrm{~kg}$ of apples per day. However, no reports are available on the effect of NCS compared to refined sugar on improving oxidative stress and antioxidant system in subjects with metabolic syndrome factors. Several studies indicate that oxidative stress and chronic inflammatory conditions pave the way for developing metabolic diseases. In obese persons, persistent oxidative stress and inflammation are critical primary conditions that cause the generation of pathogens and complications of diseases (carcinogenesis, obesity, diabetes, and cardiovascular diseases) by modified cellular and nuclear pathways, including impaired DNA damage repair and cell cycle regulation [44]. Therefore, it is crucial to further study the role of NCS in improving these conditions due to its antioxidant potential.

\subsection{Anti-Inflammatory Properties}

Inflammation is a biological response of the immune system caused by various conditions, including pathogens, damaged cells, and toxins. These conditions trigger acute and/or chronic inflammatory responses in different organs, resulting in tissue damage or disease [49]. Minimal studies have highlighted that NCS can reduce the inflammatory status or produce anti-inflammatory substances. Singh et al. [47] revealed that overexposure of mice to arsenic-contaminated drinking water resulted in immunotoxicity and increased production of pro-inflammatory cytokines (interleukin- $1 \beta$, interleukin- 6 and TNF- $\alpha$ ). Concurrent intake of jaggery and arsenic in mice effectively minimized the amounts of inflammatory cytokines (interleukin-1 $\beta$, interleukin- 6 and TNF- $\alpha$ ) [47]. In another rodent model, it was found that administration of BS alone or with a high-fat diet (HFD) reduced the inflammatory state mediated by TLR4 compared with the refined sugar (RS) group [50]. The TLR4 signaling mechanisms are the primary causes of inflammatory response resulting from obesity [51]. Sánchez-Tapia et al. [52] reported that the consumption of BS decreased the expression of inflammatory response markers, maximized the level of anti-inflammatory cytokines (IL-10) and increased the concentration of sIgA. 


\subsection{Non-Centrifugal Sugar and Metabolic Syndrome}

Metabolic syndrome (MetS) involves central obesity, hypertension, insulin resistance, and atherogenic dyslipidemia [53]. In addition, MetS is tightly linked toa high chance of developing cardiovascular and neurodegenerative disease. The MetS pathogenetic process includes both genetic and acquired conditions, which modulate the inflammation and oxidative stress giving way to metabolic abnormalities [53]. Consequently, NCS might play a positive role in the various forms of the MetS due to its antioxidant biological activity, polyphenol, and mineral content.

\subsubsection{Anti-Obesity Effect}

Obesity is the pivotal point of MetS. The preventive effect of NCS against obesity has been investigated in animal studies. For example, short-term feeding for 42 days with $15 \%$ BS caused a significant reduction of weight gain in rats compared to those fed with RS [54]. Similarly, prolonged intake of $10 \%$ BS for 4 months showed less effect on body weight and body fat than RS or artificial sweeteners [52]. Animals fed RS had $209 \mathrm{~g}$ of fat mass, and rats fed sucralose had $165 \mathrm{~g}$ of fat mass, while animals fed BS had $125 \mathrm{~g}$ of fat mass, by the way, similar to the control group (125.2 $\mathrm{g}$ of fat mass) [52]. In another study, administration of BS for 4 months effectively averted overall weight gain in adult rats compared to the rat's receiving RS [50]. Indeed, consumption of BS in the rat model resulted in a smaller adipocyte size of white and brown adipose tissue than RS [50]. Enlarged adipocytes recruit macrophages and trigger inflammation and the release of factors that reduce insulin sensitivity. BS also increased the functionality of adiposity by increasing adiponectin in white adipose tissue and an increase in uncoupling protein-1 (UCP-1) in brown adipose tissue [50]. Dysregulation of signaling pathways in adipose tissue can contribute to the development of obesity. The potassium content of this natural sweetener is also believed to assist in weight management, since it prevents water retention in the body improve food metabolism [14]. Due to the promising effects of NCS in weight management observed by different studies and its role in improving the functionality of adiposity, further studies would aid the clarification of the role of NCS consumption on weight maintenance.

\subsubsection{Antidiabetic Effect}

Type 2 diabetes mellitus (T2DM) has become an epidemic of non-communicable diseases, with 415 million people presently suffering from diabetes around the world. According to the International Diabetes Federation, around 5 million persons died from DM in 2015, and the survey predicts that there will be about 642 million diabetic patients by 2040 [55]. A core characteristic of T2DM is hyperglycaemia due to high liver glucose levels, insulin resistance, and abnormal production of pancreatic insulin [55]. Present control of T2DM in the clinical environment includes a large-scale examination of the overall population, change of habits and weight management, and pharmacological attention as the final option [56]. Since a long time ago, researchers have been conducting several clinical and preclinical studies to investigate the beneficial effects of natural sweeteners on diabetes management [57-59]. Indeed, RS is readily absorbed in the blood, and high amounts of energy are released rapidly. Therefore, it is not recommended for diabetic people. While NCS is digested slowly and the energy release is also slow, it is a better and healthier alternative for a diabetic [50]. Several attempts have been made to understand the role of NCS in glucose metabolism and insulin resistance.

In 1984, Kimura et al. [60] revealed that the non-sugar fraction of kokuto prevented the rise of insulin secretion in rats fed a high refined sugar diet for two months and with no increased blood glucose level. Moreover, it was reported that this non-sugar fraction prevented the adsorption of glucose and fructose from the small intestine of rats. These benefits were attributed to the presence of 3,4-dimethyl-phenyl-O-D-glucoside and 3,4,6trimethoxy-phenyl-O-D-glucoside (BS-1). Recently, Shamsi-Goushki et al. [54] investigated the effect of $15 \%$ RS or BS solution on insulin resistance, weight gain and serum level 
of brain-derived neurotrophic factor (BDNF) in healthy Wistar rats for 42 days. It was found that the adverse effects of BS on these factors were less than those of RS. The serum level of BDNF was less in the RS group due to higher insulin resistance and weight gain observed in the RS group compared to that of the BS group. The effectiveness of BS on insulin resistance and consequently, higher BDNF levels were attributed to chromium and antioxidant compounds.

BDNF helps to develop and maintain the nervous system health and synaptic plasticity. BDNF has an additional role in metabolic control, especially in glucose metabolism and insulin resistance [61]. The blood level of BDNF was lower in individuals with insulin resistance and hyperglycaemia [60]. Future research is required to investigate the impacts of various dosages of RS and BS on biochemical profiles in healthy and diabetic subjects. Histology of different organs and immunohistochemistry also were not examined. In another investigation, $10 \%$ feeding of BS for rats, maintained glucose tolerance similar to the control group, in spite of the intake of an HFD. In contrast, the group fed RS showed glucose intolerance [52]. Likewise, long-term consumption of $10 \%$ BS for 4 months maintains almost normal glucose and insulin levels while RS produces hyperglycemia and hyperinsulinemia [50]. The authors also reported that rats fed with RS promoted the expression of GLUT 2 in the enterocytes, increasing the glucose transport and the most elevated blood glucose levels compared to rats fed with BS. A surge in GLUT2 has been reported in obese subjects linked to low insulin sensitivity and hyperglycemia [62]. Rats fed on BS showed a better insulin sensitivity by controlling the phosphorylation level of IRS $_{\text {tyr }}$ and Akt and increased white adipose GLUT 4 expression compared to rats fed on RS that showed insulin resistance [50]. Transgenic rodents lack GLUT 4 to reduce overall-body insulin sensitivity [63]. Another recent study reported that administering $1 \mathrm{~g} / \mathrm{kg}$ of jaggery to alloxan-induced diabetic rats did not show any significant benefits over metabolic health [64]. However, glucose level and weight gain were the only parameters that have been measured as an indicator of the beneficial effect on the diabetic subject.

One possible mechanism behind the effectiveness of NCS to control blood glucose depends on its capability to hinder $\alpha$-glucosidase functions. $\alpha$-amylase is the enzyme that hydrolyses complex starch to oligosaccharides, while alpha-glucosidase is responsible for the hydrolysis of different forms of oligosaccharides into monosaccharides as the final products. It is noteworthy that suppression of such enzymes could reduce postprandial blood glucose levels [65]. Accordingly, the antidiabetic capacity of a different variety of unrefined brown sugar was examined using in vitro alpha-amylase and alpha-glucosidase enzyme retardation assays [46]. Different varieties of BS showed $\alpha$-Glucosidase inhibitory properties in the range of $25 \%$ to $50 \%$, which was correlated with high phenolic content and radical scavenging capacity [46]. Thus, it was suggested that total phenolic content might be linked to the capability of cane sugar to hinder this enzyme. Furthermore, a significant effect of the sugar color was noticed on the anti-diabetes and antioxidant effect, especially among sugar cane derivatives [46].

Additionally, NCS minerals content, particularly selenium or chromium, could represent a relevant component in regulating glucose and insulin levels because they were reported to improve the diabetic condition [13,23]. Chromium is an essential element that enhances insulin activity. Previous reports showed that patients with T2DM have lower blood chromium levels than those devoid of the disease [66]. The mechanism of action in which chromium was able to control or prevent diabetes includes improving insulin attachment to cells, insulin receptor number, and activation of insulin receptor kinase, thus reducing insulin resistance [67]. On the other hand, selenium is an insulin mimic [22], where it was recorded to exhibit several insulin-like actions both in vivo and in vitro. These insulin-like actions promote glucose digestion and control metabolism (glycolysis, gluconeogenesis, fatty acid synthesis) and the pentose phosphate pathway [22,68]. Additional studies in animal and human trials are required to determine the biological role of NCS in diabetes management and its complication, and to elucidate metabolic pathways. 


\subsubsection{Hypolipidemic Effect of NCS}

The significant components of dyslipidemia include increased transport of free fatty acids from visceral adipose tissue to the liver, high level of fasting and postprandial triglycerides (TGs), low-density lipoproteins (LD L) and total cholesterol (TC) and reduced level of high-density lipoproteins (HDL) [69]. Thus, dyslipidemia increases atherosclerotic cardiovascular risk. In 1984, Kimura et al. [60] showed that the non-sugar fraction of kokuto hindered the increase of blood TGs and lipid peroxidase of rats fed a high RS diet for two months. Inafuku et al. [70] validated these results in an apolipoprotein E-deficient-mice, reporting that consumption of kokuto lowered hepatic TGs levels. The hypolipidemic effect of NCS might be due to policosanols (PCs), a mixture of primary long-chain alcohols that have cholesterol and lipid-reducing abilities [1,21]. Okabe et al. [15] reported that enhancing the diet with kokuto, and its phenolic extract and PCs hindered the development of atherosclerosis in Japanese quail. Additionally, there was a significant negative correlation between the radical scavenging property measured in the blood and the rate of atherosclerosis in the dietary groups. Therefore, it was concluded that the hypolipidemic effect of NCS was not only due to the presence of PCs but also phenolic compounds of NCS plays a significant function in the suppression of experimental atherosclerosis by controlling the oxidative stress in the aortic lesion.

\subsection{NCS and Neurodegeneration}

ROS production could facilitate mitochondrial dysfunction and the oxidation of various macromolecules in cells. This condition was shown to be connected with the progression of neurodegenerative diseases like Alzheimer's disease and Parkinson's disease [71]. In such a disease, neurons situated in the substantia nigra of the brain, predominantly dopamine-producing neurons, are harmed by three primary dysfunctions: oxidative stress, mitochondrial respiration defect and abnormal protein aggregation [71]. Recently, the neuroprotective effects of sugarcane derivatives (Syrop, Juices, stalk and NCS) were evaluated by determining the cytotoxicity, mitochondrial membrane potential, monoaminoxidase $\mathrm{B}$ activity and apoptosis of a Parkinson's disease (PD)-induced model [18]. In the PD-induced model, the presence of sugarcane derivatives lowered cytotoxicity by about $50 \%$, as measured by both 3-(4,5-dimethylthiazol-2-yl)-2,5-diphenyltetrazolium bromide (MTT) and lactate dehydrogenase (LDH) assays.

Furthermore, intracellular inhibition of mitochondrial enzyme monoaminoxidase B (MAO-B) was increased when the PD-induced model cells were exposed to high concentrations of SC products. High expression of MAO-B has been linked to PD [72]. Moreover, sugarcane derivatives indicated a significant biological reversion and recovering effect of the mitochondrial membrane potential and halted the development of early apoptosis. The observed inherent effects on mitochondrial function encourage developing new brain injury treatments and neurodegenerative disorders [73]. The neuroprotective effects of sugarcane derivatives attributed to the presence of different molecules belong to the family of flavonoids and bioactive phenolic acids, particularly ferulic acid [18]. However, studies on the effect of NCS on brain ageing and neurodegenerative disorder are rare. More animal and human investigations are needed to confirm the current knowledge in this area. Furthermore, additional investigations should be conducted to explain the molecular mechanisms responsible for improving neurodegeneration.

\section{Safety of NCS}

Overall, various forms of cane sugar are not toxic sweeteners universally consumed [23]. However, chromium [45] and acrylamide [74] are present in unrefined case sugar, which resulted from the harvest stage and transformation. It was previously reported that acrylamide exposure might lead to various forms of cancer [75,76]. Within the body, acrylamide is changed into glycidamide, which lead to DNA impairment. Nevertheless, epidemiological reports in humans have shown no concrete supporting facts that dietary acrylamide exposure is linked to the chance of any cancer $[75,77]$. Furthermore, acrylamide generation 
might be avoided or reduced by regulating various manufacturing process criteria [78] For example, harmful trace elements arsenic, bromine, mercury, antimony and selenium were determined in NCS jaggery in Pakistan. However, their content is tolerated in human systems [79]. Moreover, polycyclic aromatic hydrocarbons (PAHs) contaminants generated in the manufacture of sugarcane products, are present in $80 \%$ of tested samples of NCS in Brazil ranging from 0.07 to $4.03 \mu \mathrm{g} \mathrm{kg}^{-1}$ (no safety levels have been recorded for PAHs) [80]. The components of various inorganic anions: chloride, phosphate, nitrate, nitrite, sulphate, and organic acids: lactic, acetic, formic, malic and citric, might be utilized as essential parameters of the grade of industrial NCS [81].

In addition, several studies have addressed the toxicity and cytotoxicity effect of NCS. Cifuentes et al. [18] demonstrate the non-cytotoxic activity of NCS on the induced Parkinson's model by MTT and LDH assays after $48 \mathrm{~h}$ of exposure, even at the highest recorded concentration of $8 \mathrm{mg} / \mathrm{mL}$. In another study, MRBS and BS were not cytotoxic to 3T3-L1 adipocytes, and the cells exposed to the mentioned sugar had 100\% viability [23]. BS samples did not show any harmful impact on NIH 3T3 cell viability at the concentration of $2.5 \mathrm{mg} / \mathrm{g}$ [20]. The zebrafish embryotoxicity test was also performed to evaluate the toxicity of bioactive compounds in BS and MRBS [23]. The embryos exposed to BS and MRBS showed high viability, indicating that both forms of BS were not toxic to zebrafish embryos. $\mathrm{LD}_{50}$ was not recorded because no toxic effect was noticed even at the highest concentration investigated for both sugars. In any case, the phytochemicals in MRBS, such as 4-hydroxy- benzoic acid, chlorogenic acid, protocatechuic acid and trans-Ferulic acid, within the concentration range of $5-10 \mathrm{mg} / \mathrm{mL}$, were able to decrease the heart rate of the zebrafish embryos and showed potential cardiotoxicity compared to BS.

\section{Conclusions and Future Marks}

With the increasing global attention on healthy products and the impact of diet on lowering the chance of chronic disorders, unrefined sugar has presently captured the interest of health-conscious consumers, and opportunities to provide sugar to growing healthy food markets have skyrocketed [32,82]. NCS is a natural sweetener and rich in phytochemical molecules like flavonoids and phenolic acids with therapeutic properties. Immense experimental facts suggest that NCS might benefit human health, including hypoglycemic effects, improving insulin sensitivity, weight management, hypolipidemic effects, reducing inflammation and oxidative stress and protecting from neurodegenerative disease. However, since NCS generated many interests as a healthier sweetener with therapeutic potential, there is a need to highlight further crucial deductions in the scientific literature. First, the mechanisms attributed to the benefits of NCS require more elucidation; carefully monitored investigations on humans and animals are required before considering NCS a functional product. Second, in the studies related to potential health benefits of NCS, there should be more clarifications on the exact characteristics of the experimented unrefined sugar. Generally, brown sugar can be found in many forms with different characteristics (centrifuged or non-centrifuged and dark or light), significantly influencing the pharmacological activity and phytochemical compounds. Thirdly, grades of unrefined sweeteners seem to be different between batches due to the variation in the source materials and the use of non-standard processing technologies adopted by small-scale and cottage industries $[83,84]$.

Nonetheless, several multinational companies manufacture branded unrefined sugar with standard characteristics in all production lots. Therefore, consumers in contemporary times are concerned about unrefined sweeteners from multinational companies because of their unique quality. Hence, an analysis of branded commercial sugar physicochemical, nutritional qualities, and biological properties is highly encouraged to inform consumer choice. 


\begin{abstract}
Author Contributions: Conceptualization, D.Z.; methodology, D.Z.; investigation, D.Z. and A.A.; resources, A.A.; writing—original draft preparation, D.Z.; writing—review and editing, A.A.; supervision, A.A.; project administration, A.A. All authors have read and agreed to the published version of the manuscript.
\end{abstract}

Funding: This research was funded by Central Sugar Refinery Sdn Bhd, grant number 6300256-14001.

Institutional Review Board Statement: Not applicable.

Informed Consent Statement: Not applicable.

Acknowledgments: We would like to acknowledge Central Sugar Refinery Sdn Bhd, Malaysia for providing us with the research funding.

Conflicts of Interest: The authors declare no conflict of interest.

\title{
References
}

1. Weerawatanakorn, M.; Asikin, Y.; Kamchonemenukool, S.; Tamaki, H.; Takara, K.; Wada, K. Physicochemical, antioxidant, volatile component, and mass spectrometry-based electronic nose analyses differentiated unrefined non-centrifugal cane, palm, and coconut sugars. J. Food Meas. Charact. 2021, 15, 1563-1577. [CrossRef]

2. FAO. Definition and Classification of Commodities. Sugar Crops and Sweeteners and Derived Products. Available online: http:/ / www.fao.org/es/faodef/fdef03e.HTM (accessed on 9 October 2021).

3. WCO (World Customs Organization). HS Nomenclature 2012 Edition, Section 0417-2012E, Chapter 17, Sugar and Sugar Confectionery. Available online: https://www.wcoomd.org/en/faq/ \{\}/link.aspx?_id=3F9BB5F791484D45810FE0A5B9782E4 C\&_Z=Z (accessed on 9 October 2021).

4. Liu, J.; Wan, P.; Xie, C.; Chen, D.W. Key aroma-active compounds in brown sugar and their influence on sweetness. Food Chem. 2021, 345, 128826. [CrossRef]

5. Asikin, Y.; Kamiya, A.; Mizu, M.; Takara, K.; Tamaki, H.; Wada, K. Changes in the physicochemical characteristics, including flavour components and Maillard reaction products, of non-centrifugal cane brown sugar during storage. Food Chem. 2014, 149, 170-177. [CrossRef]

6. Velásquez, F.; Espitia, J.; Mendieta, O.; Escobar, S.; Rodríguez, J. Non-centrifugal cane sugar processing: A review on recent advances and the influence of process variables on qualities attributes of final products. J. Food Eng. 2019, 255, 32-40. [CrossRef]

7. Mohan, N.; Singh, P. (Eds.) Sugar and Sugar Derivatives: Changing Consumer Preferences; Springer: Singapore, 2020. [CrossRef]

8. Asikin, Y.; Takahara, W.; Takahashi, M.; Hirose, N.; Ito, S.; Wada, K. Compositional and Electronic Discrimination Analyses of Taste and Aroma Profiles of Non-Centrifugal Cane Brown Sugars. Food Anal. Methods 2017, 10, 1844-1856. [CrossRef]

9. Asikin, Y.; Takahashi, M.; Hirose, N.; Hou, D.X.; Takara, K.; Wada, K. Wax, policosanol, and long-chain aldehydes of different sugarcane (Saccharum officinarum L.) cultivars. Eur. J. Lipid Sci. Technol. 2012, 114, 583-591. [CrossRef]

10. Cai, H.; Steward, W.P.; Gescher, A.J. Determination of the putative cancer chemopreventive flavone tricin in plasma and tissues of mice by HPLC with UV-visible detection. Biomed. Chromatogr. 2005, 19, 518-522. [CrossRef]

11. Colombo, R.; Yariwake, J.H.; Queiroz, E.F.; Ndjoko, K.; Hostettmann, K. On-line identification of sugarcane (Saccharum officinarum L.) methoxyflavones by liquid chromatography-UV detection using post-column derivatization and liquid chromatography-mass spectrometry. J. Chromatogr. A 2005, 1082, 51-59. [CrossRef]

12. Duarte-almeida, J.M.; Salatino, A.; Inés, M.; Lajolo, F.M. Phenolic composition and antioxidant activity of culms and sugarcane (Saccharum officinarum L.) products. Food Chem. 2021, 125, 660-664. [CrossRef]

13. Jaffé, W.R. Health Effects of Non-Centrifugal Sugar (NCS): A Review. Sugar Tech 2012, 14, 87-94. [CrossRef]

14. Hirpara, P.; Thakare, N.; Patel, D.; Kele, V.D. Jaggery: A natural sweetener. J. Pharmacogn. Phytochem. 2020, 9, 3145-3148. Available online: https:/ / www.phytojournal.com (accessed on 21 December 2021).

15. Okabe, T.; Toda, T.; Inafuku, M.; Wada, K.; Iwasaki, H.; Oku, H. Antiatherosclerotic function of Kokuto, Okinawan non-centrifugal cane sugar. J. Agric. Food Chem. 2009, 57, 69-75. [CrossRef]

16. Harish Nayaka, M.A.; Sathisha, U.V.; Manohar, M.P.; Chandrashekar, K.B.; Dharmesh, S.M. Cytoprotective and antioxidant activity studies of jaggery sugar. Food Chem. 2009, 115, 113-118. [CrossRef]

17. Seguí, L.; Calabuig-Jiménez, L.; Betoret, N.; Fito, P. Physicochemical and antioxidant properties of non-refined sugarcane alternatives to white sugar. Int. J. Food Sci. 2015, 50, 2579-2588. [CrossRef]

18. Cifuentes, J.; Salazar, V.A.; Cuellar, M.; Castellanos, M.C.; Rodríguez, J.; Cruz, J.C.; Muñoz-Camargo, C. Antioxidant and neuroprotective properties of non-centrifugal cane sugar and other sugarcane derivatives in an in vitro induced parkinson's model. Antioxidants 2021, 10, 1040. [CrossRef] [PubMed]

19. Jaffé, W.R. Nutritional and functional components of non-centrifugal cane sugar: A compilation of the data from the analytical literature. J. Food Compost. Anal. 2015, 43, 194-202. [CrossRef]

20. Lee, J.S.; Ramalingam, S.; Guk Jo, I.; Som Kwon, Y.; Bahuguna, A.; Sook Oh, Y.; Kwon, O.-J.; Kim, M. Comparative study of the physicochemical, nutritional, and antioxidant properties of some commercial refined and non-centrifugal sugars. Food Res. Int. 2019, 122, 563. [CrossRef] [PubMed] 
21. Meerod, K.; Weerawatanakorn, M.; Pansak, W. Effect of Liming Process on Physicochemical Properties and Phytochemical Components of Non-Centrifugal Sugar from Different Sugarcane Cultivars. Agric. Res. 2020, 9, 35-45. [CrossRef]

22. Alarcón, A.L.; Palacios, L.M.; Osorio, C.; César Narváez, P.; Heredia, F.J.; Orjuela, A.; Hernanz, D. Chemical characteristics and colorimetric properties of non-centrifugal cane sugar ("panela") obtained via different processing technologies. Food Chem. 2021, 340, 128183. [CrossRef]

23. Azlan, A.; Khoo, H.E.; Sajak, A.A.B.; Aizan Abdul Kadir, N.A.; Yusof, B.N.M.; Mahmood, Z.; Sultana, S. Antioxidant activity, nutritional and physicochemical characteristics, and toxicity of minimally refined brown sugar and other sugars. Food Sci. Nutr. 2020, 8, 5048-5062. [CrossRef]

24. EFSA Panel on Dietetic Products, Nutrition and Allergies (NDA). Scientific Opinion on the substantiation of a health claim related to iron and contribution to normal formation of haemoglobin and red blood cells pursuant to Article 14 of Regulation (EC) No 1924/2006. EFSA J. 2014, 12, 3515. [CrossRef]

25. Fontenelle, L.C.; Feitosa, M.M.; Morais, J.B.S.; Severo, J.S.; de Freitas, T.E.C.; Beserra, J.B.; Henriques, G.S.; Marreiro, D.D.N. The role of selenium in insulin resistance. Braz. J. Pharm. Sci. 2018, 54, 1-11. [CrossRef]

26. Ngo, D.-H.; Vo, T.S. An Updated Review on Pharmaceutical Properties of Gamma-Aminobutyric Acid. Molecules 2019, $24,2678$. [CrossRef]

27. Funane, K.; Tokashiki, T.; Gibu, S.; Kawabata, Y.; Oguma, T.; Ito, H.; Nakachi, M.; Miyagi, S.; Kobayashi, M. Finding of Cyclodextrans and Attempts of their Industrialization for Cariostatic Oligosaccharides. J. Appl. Glycosci. 2007, 54, 103-107. [CrossRef]

28. Oshima, H.; Kimura, I.; Izumori, K. Psicose contents in various food products and its origin. Food Sci. Technol. 2006, 12, 137-143. [CrossRef]

29. Weerawatanakorn, M.; Asikin, Y.; Takahashi, M.; Tamaki, H.; Wada, K.; Ho, C.T.; Chuekittisak, R. Physico-chemical properties, wax composition, aroma profiles, and antioxidant activity of granulated non-centrifugal sugars from sugarcane cultivars of Thailand. J. Food Sci. Technol. 2016, 53, 4084-4092. [CrossRef]

30. Tsao, R. Chemistry and biochemistry of dietary polyphenols. Nutrients 2010, 2, 1231-1246. [CrossRef]

31. Barrera, C.; Betoret, N.; Seguí, L. Phenolic Profile of Cane Sugar Derivatives Exhibiting Antioxidant and Antibacterial Properties. Sugar Tech 2020, 22, 798-811. [CrossRef]

32. Eggleston, G.; Aita, G. Exploration of sugarcane products as a major source of antioxidant phenolic extracts in commercial foods and beverages. Int. Sugar J. 2020, 126, 690-696.

33. Shang, Y.; Xie, C.; Meng, L.; Cui, F.; Lu, H.; Li, W.; Li, K. Polyphenol Profiles and Antioxidant Activities of Non-centrifugal Sugars Derived from Different Varieties of Membrane-Clarified Sugarcane Juice. Sugar Tech 2021, 23, 1-12. [CrossRef]

34. Zhu, Z.; Xie, C.; Li, W.; Hang, F.; Li, K.; Shi, C.; Doherty, W.O.S. Nutritional and antioxidant properties of non-centrifugal cane sugar derived from membrane clarified juice. LWT 2020, 131, 109717. [CrossRef]

35. Kinjo, Y.; Takahashi, M.; Hirose, N.; Mizu, M.; Hou, D.X.; Wada, K. Anti-stress and antioxidant effects of non- centrifuged cane sugar, Kokuto, in restraint-stressed mice. J. Oleo Sci. 2019, 68, 183-191. [CrossRef]

36. Eggleston, G.; Aita, G.; Triplett, A. Circular Sustainability of Sugarcane: Natural, Nutritious, and Functional Unrefined Sweeteners That Meet New Consumer Demands. Sugar Tech 2021, 23, 964-973. [CrossRef]

37. Eggleston, G. Positive aspects of cane sugar and sugar cane derived products in food and nutrition. J. Agric. Food Chem. 2018, 66, 4007-4012. [CrossRef] [PubMed]

38. Phillips, K.M.; Carlsen, M.H.; Blomhoff, R. Total antioxidant content of alternatives to refined sugar. J. Am. Diet. Assoc. 2009, 109, 64-71. [CrossRef] [PubMed]

39. Azlan, A.; Ebadi, S.; Yusof, B.N.M.; Othman, N.M.H.; Kannar, D.; Sultana, S.; Mahmood, Z. Determination of Satiety, Glycaemic Profiles, Total Antioxidant Capacity and Postprandial Glycemic Responses of Minimally Refined Sugar and Others in Malaysian Healthy Adults. Nutrition, 2021; in press. [CrossRef]

40. Salgo, A.; Nagy, J.; Mikó, É.; Boros, I. Application of near infrared spectroscopy in the sugar industry. J. Near Infrared Spectrosc. 1998, 6, A101-A106. [CrossRef]

41. Harbeck, C.; Faurie, R.; Scheper, T. Application of near-infrared spectroscopy in the sugar industry for the detection of betaine. Anal. Chim. Acta 2004, 501, 249-253. [CrossRef]

42. Gajdoš Kljusurić, J.; Mihalev, K.; Bečić, I.; Polović, I.; Georgieva, M.; Djaković, S.; Kurtanjek, Ž. Near-infrared spectroscopic analysis of total phenolic content and antioxidant activity of berry fruits. Food Technol. Biotechnol. 2016, 54, 236-242. [CrossRef]

43. Closed Loop Sugar Processing. Available online: https://shop.exchange.se.com/en-US/apps/60696/closed-loop-sugarprocessing (accessed on 21 December 2021).

44. Roberts, C.K.; Sindhu, K.K. Oxidative stress and metabolic syndrome. Life Sci. 2009, 84, 705-712. [CrossRef]

45. Iqbal, M.; Afzal Qamar, M.; Bokhari, T.H.; Abbas, M.; Hussain, F.; Masood, N.; Keshavarzi, A.; Qureshi, N.; Nazir, A. Total phenolic, chromium contents and antioxidant activity of raw and processed sugars. Inf. Processing Agric. 2017, 4, 83-89. [CrossRef]

46. Ranilla, L.G.; Kwon, Y.I.; Genovese, M.I.; Lajolo, F.M.; Shetty, K. Antidiabetes and antihypertension potential of commonly consumed carbohydrate sweeteners using in vitro models. J. Med. Food 2008, 11, 337-348. [CrossRef]

47. Singh, N.; Kumar, D.; Lal, K.; Raisuddin, S.; Sahu, A.P. Adverse health effects due to arsenic exposure: Modification by dietary supplementation of jaggery in mice. Toxicol. Appl. Pharmacol. 2010, 242, 247-255. [CrossRef] 
48. Grabek-Lejko, D.; Tomczyk-Ulanowska, K. Phenolic content, antioxidant and antibacterial activity of selected natural sweeteners available on the Polish market. J. Environ. Sci. Health B 2013, 48, 1089-1096. [CrossRef] [PubMed]

49. Chen, L.; Deng, H.; Cui, H.; Fang, J.; Zuo, Z.; Deng, J.; Li, Y.; Wang, X.; Zhao, L. Inflammatory responses and inflammationassociated diseases in organs. Oncotarget 2018, 9, 7204-7218. [CrossRef] [PubMed]

50. Sánchez-Tapia, M.; Martínez-Medina, J.; Tovar, A.R.; Torres, N. Natural and artificial sweeteners and high fat diet modify differential taste receptors, insulin, and TLR4-mediated inflammatory pathways in adipose tissues of rats. Nutrients 2019, 11, 880. [CrossRef] [PubMed]

51. Rogero, M.M.; Calder, P.C. Obesity, inflammation, toll-like receptor 4 and fatty acids. Nutrients 2018, 10, 432. [CrossRef] [PubMed]

52. Sánchez-Tapia, M.; Miller, A.W.; Granados-Portillo, O.; Tovar, A.R.; Torres, N. The development of metabolic endotoxemia is dependent on the type of sweetener and the presence of saturated fat in the diet. Gut Microbes 2020, 12, 1801301. [CrossRef]

53. Alberti, K.G.M.M.; Zimmet, P.; Shaw, J. Metabolic syndrome-A new world-wide definition. A consensus statement from the international diabetes federation. Diabet. Med. 2006, 23, 469-480. [CrossRef]

54. Shamsi-Goushki, A.; Mortazavi, Z.; Mirshekar, M.A.; Behrasi, F.; Moradi-Kor, N.; Taghvaeefar, R. Effects of high white and brown sugar consumption on serum level of brain-derived neurotrophic factor, insulin resistance, and body weight in albino rats. J. Obes. Metab. Syndr. 2021, 29, 320-324. [CrossRef]

55. Burgeiro, A.; Cerqueira, M.G.; Varela-Rodríguez, B.M.; Nunes, S.; Neto, P.; Pereira, F.C.; Reis, F.; Carvalho, E. Glucose and Lipid Dysmetabolism in a Rat Model of Prediabetes Induced by a High-Sucrose Diet. Nutrients 2017, 9, 638. [CrossRef] [PubMed]

56. Chawla, R.; Madhu, S.; Makkar, B.; Ghosh, S.; Saboo, B.; Kalra, S. RSSDI-ESI clinical practice recommendations for the management of type 2 diabetes mellitus 2020. Indian J. Endocrinol. Metab. 2020, 24, 1-122. [CrossRef]

57. Ramli, N.Z.; Chin, K.Y.; Zarkasi, K.A.; Ahmad, F. A review on the protective effects of honey against metabolic syndrome. Nutrients 2018, 10, 1009. [CrossRef] [PubMed]

58. Nagai, N.; Ito, Y.; Taga, A. Comparison of the enhancement of plasma glucose levels in type 2 diabetes Otsuka Long-Evans Tokushima Fatty rats by oral administration of sucrose or maple syrup. J. Oleo Sci. 2013, 62, 737-743. [CrossRef]

59. Mejia, E.; Pearlman, M. Natural Alternative Sweeteners and Diabetes Management. Curr. Diab. Rep. 2019, 19, 142. [CrossRef] [PubMed]

60. Kimura, Y.; Okuda, H.; Arichi, S. Effects on non-sugar fraction in black sugar on lipid and carbohydrate metabolism; Part I. Planta Med. 1984, 50, 465-468. [CrossRef] [PubMed]

61. Rozanska, O.; Uruska, A.; Zozulinska-Ziolkiewicz, D. Brain-derived neurotrophic factor and diabetes. Int. J. Mol. Sci. 2020, 21, 841. [CrossRef]

62. Ait-Omar, A.; Monteiro-Sepulveda, M.; Poitou, C.; Le Gall, M.; Cotillard, A.; Gilet, J.; Garbin, K.; Houllier, A.; Château, D.; Lacombe, A.; et al. GLUT2 accumulation in enterocyte apical and intracellular membranes: A study in morbidly obese human subjects and ob/ob and high fat-fed mice. Diabetes 2011, 60, 2598-2607. [CrossRef]

63. Leguisamo, N.M.; Lehnen, A.M.; Machado, U.F.; Okamoto, M.M.; Markoski, M.M.; Pinto, G.H.; Schaan, B.D. GLUT4 content decreases along with insulin resistance and high levels of inflammatory markers in rats with metabolic syndrome. Cardiovasc. Diabetol. 2012, 11, 100. [CrossRef]

64. Anjum, A. Comparative Effects of Cane Sugar, Honey \& Jaggery on Plasma Glucose Level \& Body Weight of Alloxan Induced Diabetic Rats. Proc. Shaikh Zayed Med. Complex Lahore 2021, 35, 44-49. [CrossRef]

65. Ganeshpurkar, A.; Diwedi, V.; Bhardwaj, Y. In vitro $\alpha$-amylase and $\alpha$-glucosidase inhibitory potential of Trigonella foenumgraecum leaves extract. Ayu 2013, 34, 109. [CrossRef]

66. Cefalu, W.T.; Hu, F.B. Role of Chromium in Human Health and in Diabetes. Diabetes Care 2004, 27, 2741-2751. [CrossRef]

67. Hummel, M.; Standl, E.; Schnell, O. Chromium in metabolic and cardiovascular disease. Horm. Metab. Res. 2007, 39, 743-751. [CrossRef]

68. Stapleton, S.R. Selenium: An insulin-mimetic. Cell. Mol. Life Sci. 2000, 57, 1874-1879. [CrossRef] [PubMed]

69. Saibandith, B.; Spencer, J.P.E.; Rowland, I.R.; Commane, D.M. Olive Polyphenols and the Metabolic Syndrome. Molecules 2017, 22, 1082. [CrossRef] [PubMed]

70. Inafuku, M.; Toda, T.; Okabe, T.; Wada, K.; Takara, K.; Iwasaki, H.; Oku, H. Effect of Kokuto, a non-centrifugal cane sugar, on the development of experimental atherosclerosis in Japanese quail and apolipoprotein E deficient mice. Food Sci. Technol. Res. 2007, 13, 61-66. [CrossRef]

71. Kim, G.H.; Kim, J.E.; Rhie, S.J.; Yoon, S. Oxidative Stress in Autoimmune and Neurodegenerative Diseases. Role Oxidative Stress Neurodegener. Dis. 2015, 24, 325-340. [CrossRef]

72. Sai, Y.; Wu, Q.; Le, W.; Ye, F.; Li, Y.; Dong, Z. Rotenone-induced PC12 cell toxicity is caused by oxidative stress resulting from altered dopamine metabolism. Toxicol. Vitr. 2008, 22, 1461-1468. [CrossRef]

73. Cenini, G.; Lloret, A.; Cascella, R. Oxidative Stress in Neurodegenerative Diseases: From a Mitochondrial Point of View. Oxidative Med. Cell. Longev. 2019, 2019, 2105607. [CrossRef] [PubMed]

74. Lasso, J.V.; Pérez, Y.T.; Suárez, F.T.; Caballero, L.C. Determinación de acrilamida en el procesamiento de la panela por cromatografía líquida (Acrylamide Determintion in the Sugar Cane Juice Process by the Liquid Chromatography Technique). Ciencia en Desarrollo 2014, 5, 99-106. [CrossRef]

75. Virk-Baker, M.K.; Nagy, T.R.; Barnes, S.; Groopman, J. Dietary Acrylamide and Human Cancer: A Systematic Review of Literature. Nutr. Cancer 2014, 66, 774-790. [CrossRef] 
76. NTP (National Toxicology Program). Technical Report on the Toxicology and Carcinogenesis Studies of Acrylamide in F344/N Rats and B6C3F1 Mice (Feed and Drinking Water Studies). Natl. Toxicol. Program 2012, 79, 1-234. [CrossRef]

77. Lipworth, L.; Sonderman, J.S.; Tarone, R.E.; McLaughlin, J.K. Review of epidemiologic studies of dietary acrylamide intake and the risk of cancer. Eur. J. Cancer Prev. 2012, 21, 375-386. [CrossRef] [PubMed]

78. Dybing, E.; Farmer, P.B.; Andersen, M.; Fennell, T.R.; Lalljie, S.P.D.; Müller, D.J.G.; Olin, S.; Petersen, B.J.; Schlatter, J.; Scholz, G.; et al. Human exposure and internal dose assessments of acrylamide in food. Food Chem. Toxicol. 2005, 43, 365-410. [CrossRef] [PubMed]

79. Waheed, S.; Rahman, S.; Gill, K.P. INAA and AAS of different products from sugar cane industry in Pakistan: Toxic trace elements for nutritional safety. J. Radioanal. Nucl. Chem. 2009, 279, 725-731. [CrossRef]

80. Silva, F.S.; Cristale, J.; Ribeiro, M.L.; de Marchi, M.R.R. Polycyclic aromatic hydrocarbons (PAHs) in raw cane sugar (rapadura) in Brazil. J. Food Compost. Anal. 2011, 24, 346-350. [CrossRef]

81. Wojtczak, M.; Antczak, A.; Lisik, K. Contamination of commercial cane sugars by some organic acids and some inorganic anions. Food Chem. 2013, 136, 193-198. [CrossRef]

82. Drewnowski, A.; Tappy, L.; Forde, C.G.; McCrickerd, K.; Tee, E.S.; Chan, P.; Amarra, M.S. Sugars and sweeteners: Science, innovations, and consumer guidance for Asia. Asia Pac. J. Clin. Nutr. 2019, 28, 645-663.

83. Guerra, M.J.; Mujica, M.V. Physical and chemical properties of granulated cane sugar "panelas". Food Sci. Technol. 2010, 30, 250-257. [CrossRef]

84. Generoso, W.C.; Borges, M.T.M.R.; Ceccato-Antonini, S.R.; Marino, A.F.; Silva, M.V.M.; Nassu, R.T.; Verruma-Bernardi, M.R. Physical-chemical and microbiological evaluation of commercial brown sugar. J. Adolfo Lutz Inst. 2009, 68, $259-268$. 